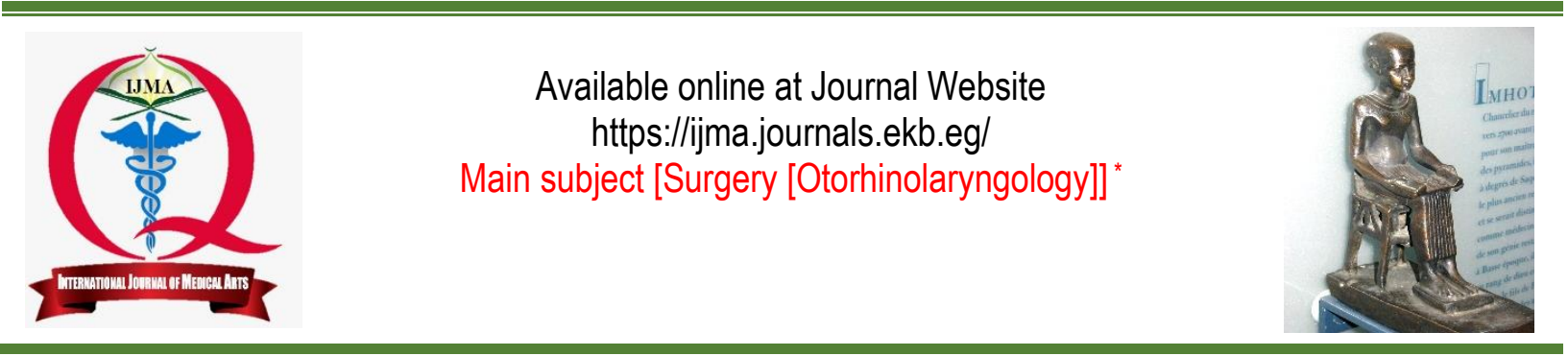

Original article

\title{
Efficacy of Modified Hyoid Bone Suspension Technique Compared to Midline Glossectomy in Management of Hypopharyngeal Obstruction in Obstructive Sleep Apnea Patients
}

\section{Osama Mohamed Refaat}

Department of Otorhinolaryngology, Faculty of Medicine, Al-Azhar University, Egypt

Email: osamarefaat78@gmail.com

Mobile: 01010439475

Received at: June 01, 2020; Revised at: July 04, 2020; Accepted at: August 02, 2020; Available online at: August 02, 2020

DOI: 10.21608/ijma.2020.106003

\section{ABSTRACT}

Background: Obstructive sleep apnea (OSA) is a common and challenging health problem, especially in adults, as it is the second most common disease related to sleep. Surgical treatment plays an important role in management of OSA. However, the optimal procedure is not yet determined.

Aim of the work: To compare between modified hyoid bone suspension and midline glossectomy in management of OSA due to hypopharyngeal obstruction.

Patients and Methods: 40 patients with OSA due to hypopharyngeal obstruction were randomly assigned to either modified hyoid bone suspension (group A; 20 patients) or midline glossectomy (group B; 20 patients). All had been assessed by full history, clinical examination and Lab investigations and underwent pre-assigned surgical intervention. Indicators of OSA such as minimal oxygen saturation, Apnea hypopnea Index [AHI] and Epworth Sleepiness Scale [ESS] had been measured preoperatively and 6 months after surgery.

Results: The studied groups were comparable as patient characteristics and preoperative data. However, hyoid suspension

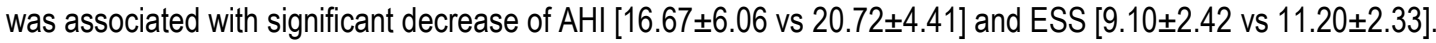
Also, minimal oxygen saturation improved significantly in group $A$ than group $B$. The percentage of responders increased significantly in group $A(75.0 \%$ vs $40.0 \%$ respectively).

Conclusion: Modified hyoid suspension is superior than the midline glossectomy, as a safer and more effective procedure for treatment of OSA due to hypopharyngeal obstruction.

Keywords: Obstructive sleep apnea; Apnea hypopnea index; Midline glossectomy; Hyoid suspension; Hypopharyngeal.

This is an open access article under the Creative Commons license [CC BY] [https://creativecommons.org/licenses/by/2.0/]

Please cite this article as: Refaat OM. Efficacy of Modified Hyoid Bone Suspension Technique Compared to Midline Glossectomy in Management of Hypopharyngeal Obstruction in Obstructive Sleep Apnea Patients. IJMA 2020; 2[3]:674-681.

* Main subject and any subcategories have been classified according to research topic. 


\section{INTRODUCTION}

Obstructive sleep apnea [OSA] is a major and challenging health problem that affect up to $4 \%$ of middle-aged males and $2 \%$ of middle-aged females. OSA with excessive day-time somnolence is about $3-7 \%$ in adult males and $2-5 \%$ in adult females. OSA prevalence do not vary significantly worldwide denoting that, OSA is as common in developing as in the developed countries $\left[{ }^{1]}\right.$.

OSA characterized by frequent attacks of upper airway collapse and obstruction during sleep. These attacks are associated with frequent desaturations of oxyhemoglobin and sleep interruptions. Severity of OSA according to apnea-hypopnea index [AHI] divided into: Mild OSA: $A H I \geq 5$ and $<15 / h$, Moderate OSA: $A H I \geq 15$ and $<30 / h$ and Severe OSA: $A H I \geq$ $30 / h[2]$.

Severe OSA is usually associated with high morbidity and mortality from cardiovascular diseases such as hypertension, myocardial infarction [MI] and cerebrovascular diseases if left without treatment ${ }^{[3]}$.

Management of OSA patients begins with recognition and treatment of predisposing or associated factors. For example, OSA patients usually have increased para-pharyngeal and tongue adipose tissue content $[4,5]$. So, weight loss can leads to improvement of hypopharyngeal collapse. Kuna et al. reported that, weight reduction is associated with long-term reduction of $\mathrm{AHI}$ in patients with type-2 diabetes. The effect of weight reduction persisting up to 4 years[6].

Continuous Positive Airway Pressure [CPAP] considered the first-line treatment for OSA. However, the previous procedures have a limited successful rate as these do not approach permanent improvement and also about $20-40 \%$ of OSA patients do not tolerate CPAP[7].

Patients who failed CPAP treatment and other conservative medical alternative should be considered for surgery[8].

Surgical treatment of OSA begins with the determination of the actual site[s] of airway narrowing or collapse which may be either retropalatal [related to the oropharynx at the level of the soft palate and tonsils] or hypopharyngeal [related to the tongue base and the hypopharynx] regions, Fujita and Simmons et al., described three patterns of obstruction: type $I$, retropalatal obstruction alone; type II, both retropalatal and hypopharyngeal obstruction; and type III, hypopharyngeal obstruction alone ${ }^{[9,10] \text {. }}$

Hypopharyngeal airway obstruction is common in OSA patients, as its prevalence about $52.5 \%$ which is associated with increased severity of OSA [11].

Fujita et al. first described uvulopalatopharyngoplasty [UPPP] as a treatment for patients with OSA which has a high success rate $50-60 \%$ in patients with retropalatal collapse [12]. However, Sher et al. reported that UPPP alone has a low success rate $5 \%$ for type II or type III OSA patients, those have hypopharyngeal element of obstruction with moderate to severe $\mathrm{AHI}{ }^{[13]}$.

The surgical management of hypopharyngeal obstruction aim to relief airway obstruction by increasing pharyngeal size, decreasing pharyngeal compliance, or both to maintain adequate air flow. There are several procedures designed to manage hypopharyngeal obstruction as tongue base reduction, genioglossal advancement and hyoid bone suspension [14].

Riley et al first reported a hyoid bone suspension as approach to release hypopharyngeal obstruction; through releasing hyoid bone from its inferior muscular attachment then suspend it with the anterior mandibular margin by using fascia lata [15]. Later they modified their technique through fixing the hyoid bone antroinferiorly over the thyroid cartilage[16].

Both procedures aim to apply tension to the hyoepiglottic ligament, which in turn enlarging the hypopharynx. However, no consensus had been found about the optimal surgical approach for OSA caused by hypopharyngeal obstruction.

\section{AIM OF THE WORK}

The current study designed to compare between modified hyoid bone suspension and midline glossectomy in treatment of hypopharyngeal obstruction in obstructive sleep apnea.

\section{PATIENTS AND METHODS}

This prospective randomized study was performed on 40 patients complaining from OSA, neither responding to conservative management nor tolerated to CPAP. All patients attended ENT 
outpatient clinics of Al-Azhar University Hospitals during the period between May 2014 and May 2016. This study was approved by the local Ethics and Research Committee of Faculty of Medicine, AlAzhar University. A written consent was obtained from all patients after full explanation of the procedure. All patients were documented as OSA with hypopharyngeal airway obstruction via overnight polysomnography and Muller maneuver through fiberoptic nasopharyngoscopy. Patients randomly allocated into two groups, group I included 20 patients, operated by using modified hyoid bone suspension procedure and group II included 20 patients, operated by transoral midline glossectomy procedure.

Full history had been taken, in presence of the bed partner with focusing on OSA manifestation i.e. daytime sleepiness which analyzed by Epworth Sleepiness Scale [ESS][17]. Full ENT examination included nasal, nasopharyngeal, oro-pharyngeal and hypopharyngeal examination. Routine laboratory investigations included [complete blood count [CBC], fasting blood sugar [FBS], prothrombin time [PT], Partial thromboplastin time [PTT], international normalized ratio [INR], clotting time, bleeding time, liver and kidney functions]. Overnight polysomnography and Muller maneuver had been performed for all patients before surgery then 6 months postoperatively. All Patients had been scheduled according to inclusion and exclusion criteria. The Inclusion criteria included those with hypopharyngeal airway obstruction (Fujita class III anatomy), moderate to severe $\mathrm{AHI}$, failed previous UPPP or tonsillectomy as a management of OSA. Exclusion criteria included those with mild $\mathrm{AHI}$, maxillofacial abnormalities [e.g., retrognathia], morbid obesity [i.e. BMI >35], central sleep apnea, anatomical nasal or oropharyngeal obstructions [i.e. deviated septum, hypertrophied turbinates, hypertrophied tonsils and redundant soft palate].

\section{Operative procedure of modified hyoid bone suspension ${ }^{[18]}$}

Under general anesthesia, patient in supine position with neck extension, $4-5 \mathrm{~cm}$ transverse skin incision at skin crease had been lined midway between the body of the hyoid bone and the thyroid notch. The dissection had been extended upward and downward through the subcutaneous tissue and platysma muscle. Upper and lower subplatysmal flaps had been elevated to expose the infrahyoid strap muscles, which had been separated and retracted laterally. The hyoid bone and thyroid cartilage had been exposed. Two stitches on each side of midline had been made with a sharp needle [proline 0] through the periosteum of the body of the hyoid bone, then each stitch had been directed to the ipsilateral thyroid lamina piercing it about $0.5 \mathrm{~cm}$ from its upper border. After returning the neck to neutral position and approximating hyoid bone to thyroid cartage, sutures had been tied simultaneously, steadily, and gently. Wound had been closed in layers with drain (Figure 1, 2)

\section{Operative procedure of midline glossectomy[19]}

Under general anesthesia, with hypotensive technique, nasotracheal tube had been inserted, patient had been placed in tonsillectomy position then tongue had been protruded outward, by fixing its proximal part by a suture, local infiltration of epinephrine 1:100000 into posterior $1 / 3$ of the tongue at both sides of the its midline had been performed, and by using Bovie coagulation electrocautery $30^{\circ}$, resected part of the tongue base had been delineated by $2 \mathrm{~cm}$ width, $5 \mathrm{~cm}$ long, it grasped by using Allis forceps to make counteraction during excision, a wedge shaped tissue portion had been excised from the tongue base which had been about $1.5-2 \mathrm{~cm}$ in depth and close to midline to avoid injury of neurovascular bundle of the tongue. After removal of midline segment of the tongue bleeding and oozing had been secured by coagulation, then gap had been closed by interrupted suture [vicryl 0]. Patients received dexamethasone $8 \mathrm{mg}$ iv intra- and post-operative for 48 hours to minimize tongue edema (Figure 3, 4).

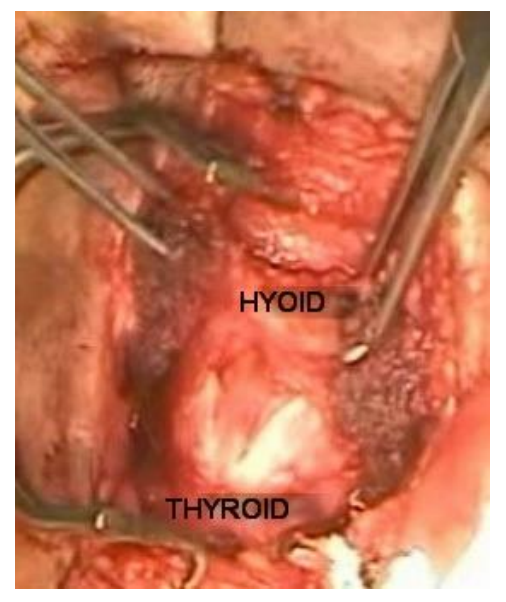

Figure (1): Exposure of hyoid bone and thyroid cartilage 


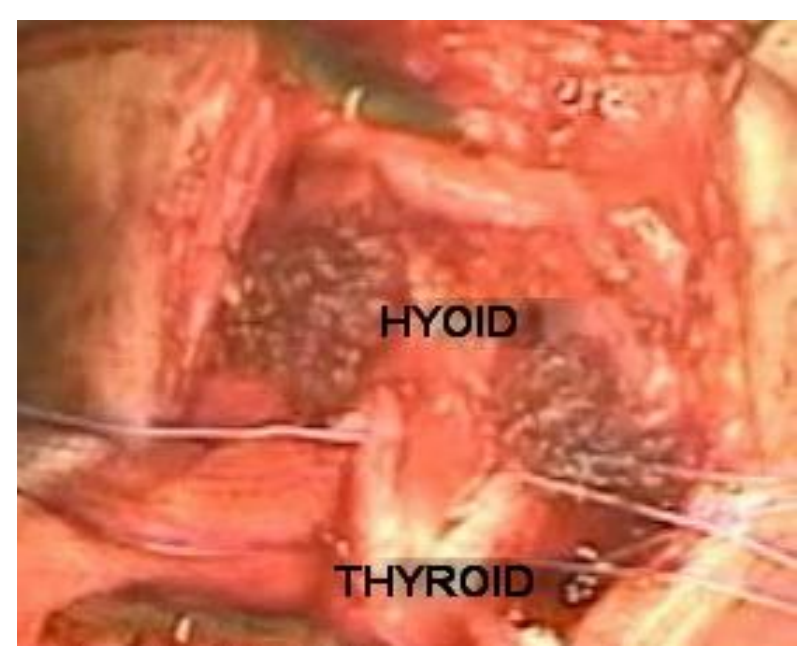

Figure (2): Approximation of hyoid bone anteroinferiorly to override thyroid cartilage by using suture

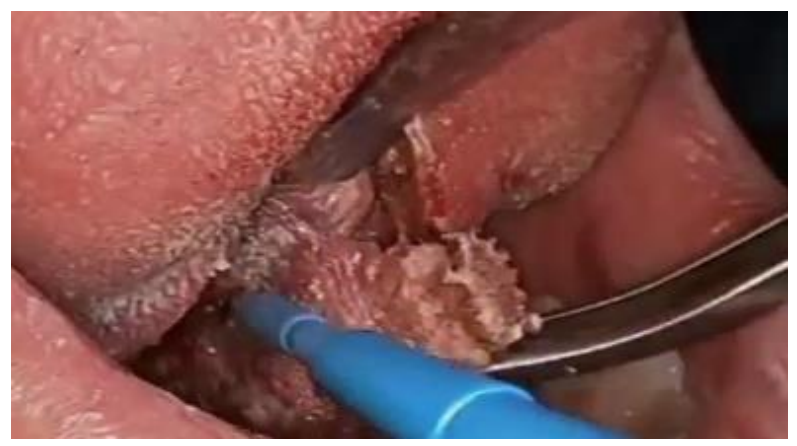

Figure (3): Excision of middle portion of the tongue base using Bovie coagulation electrocautery.

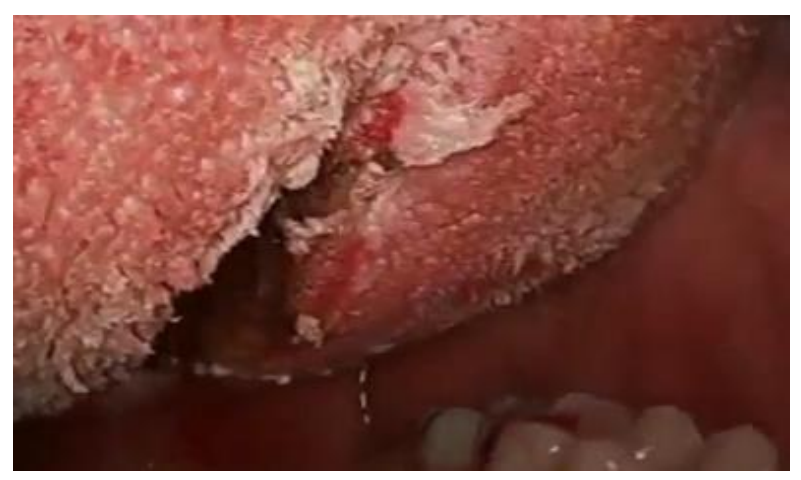

Figure (4): Gap after removal of middle portion of tongue base closed by absorbable suture

Post-operatively, all patients received oral antibiotics, analgesics, and anti-edematous drugs with oral soft diet for 7 days, with routine follow up to monitor surgical healing and manage any complications. After 6 months overnight polysomnography and Muller maneuver had been repeated.

Data analyses: for parametric data, mean (a measure of central tendency), standard deviation (a measure of dispersion) had been calculated, while for non-parametric variables, frequency and percentages had been calculated. Comparison between groups had been achieved by independent samples student's $(t)$ test or Chi square [ or Fisher exact] test according to data type. $P<0.05$ had been considered significant

\section{RESULTS}

The present work included 40 patients with confirmed diagnosis of OSA due to hypopharyngeal obstruction. They were randomly divided into two equal groups; patients in the first group underwent hypoid suspension (and in the subsequent description, we will describe it as a group A); while patients in the second group underwent to midline glossectomy (group B). Both groups were comparable regarding patient age, gender, weight, height, body mass index (BMI) and neck circumference (Table 1).

Preoperatively, both groups were comparable regarding minimal oxygen saturation, apnea index, hypopnea index, apnea hypopnea index (AHI) and Epworth Sleepiness Scale [ESS] [Table 2]. On the other side, postoperatively, there was statistically significant increase of oxygen saturation in group $A$ when compared to group B $[95.0 \pm 1.41$ vs $92.65 \pm 2.66$ respectively] and there was statistically significant decrease of apnea index in group $A$ when compared to group $B[7.16 \pm 2.22$ vs $13.71 \pm 5.69$ respectively). In addition, $\mathrm{AHI}$ was significantly decreased in group $A$ when compared to group $B$ [16.67 \pm 6.06 vs $20.72 \pm 4.41$ respectively]. Finally, ESS significantly decrease in group $A$ vs group $B$ [9.10 \pm 2.42 vs $11.20 \pm 2.33$ respectively]. Otherwise, no significant difference between groups $A$ and $B$ was observed regarding postoperative hypopnea index (Table 2)

Calculating the difference between pre- and postoperative values of variables related to OSA, both maneuvers exerts comparable effects on hypopnea index. Otherwise, the effect of hyoid suspension was significantly marked on minimal oxygen saturation apnea index, $\mathrm{AHI}$ and $\mathrm{ESS}$ than midline glossectomy [Table 3].

Finally, the percentage of responders (those who had a $50.0 \%$ or more reduction in their $\mathrm{AHI}$, or their AHI dropped to <20) was significantly higher among group A, when compared to group B $(75.0 \%$ vs $40.0 \%$ respectively) (Table 4 ). 
Refaat OM.

Table [1]: Demographic data of the studied patients

\begin{tabular}{|c|c|c|c|c|c|}
\hline \multicolumn{2}{|c|}{ Variables } & $\begin{array}{l}\text { Hyoid suspension } \\
\text { group }(n=20)\end{array}$ & $\begin{array}{c}\text { Midline glossectomy } \\
\text { group }(n=20)\end{array}$ & Test & $P$ \\
\hline \multirow[t]{2}{*}{ Sex } & Male & $16(80.0 \%)$ & $14(70.0 \%)$ & \multirow[t]{2}{*}{0.52} & \multirow[t]{2}{*}{0.35} \\
\hline & Female & $4(20.0 \%)$ & $6(30.0 \%)$ & & \\
\hline \multicolumn{2}{|c|}{ Age (years) } & $37.60 \pm 5.26 ; 28-47$ & $36.00 \pm 5.10 ; 27-43$ & 0.97 & 0.33 \\
\hline \multicolumn{2}{|c|}{ Weight } & $92.15 \pm 7.18 ; 75-109$ & $91.10 \pm 7.08 ; 77-106$ & 0.46 & 0.64 \\
\hline \multicolumn{2}{|c|}{ Height } & $172.25 \pm 8.18 ; 155-185$ & $174.60 \pm 6.69 ; 165-185$ & 0.99 & 0.32 \\
\hline \multicolumn{2}{|l|}{ BMI } & $31.16 \pm 2.71 ; 26.23-34.89$ & $29.94 \pm 2.78 ; 26-35$ & 1.40 & 0.16 \\
\hline \multicolumn{2}{|c|}{ Neck circumference } & $41.05 \pm 1.59 ; 39-44$ & $40.50 \pm 1.11 ; 39-43$ & 1.26 & 0.21 \\
\hline
\end{tabular}

BMI: Body mass index

Table (2): Pre- and postoperative data related to OSA among studied groups

\begin{tabular}{|l|l|c|c|c|c|}
\hline \multicolumn{2}{|c|}{ Variable } & Group A $(\mathrm{n}=20)$ & Group B $(\mathrm{n}=20)$ & Test & $\mathrm{P}$ \\
\hline Preoperative & Minimal SO2 & $85.04 \pm 4.67 ; 75-91$ & $86.40 \pm 4.76 ; 75-95$ & 0.91 & 0.37 \\
\cline { 2 - 6 } & Apnea index & $27.31 \pm 5.57 ; 18.40-36$ & $25.46 \pm 6.70 ; 13.20-36$ & 0.95 & 0.35 \\
\cline { 2 - 6 } & Hypopnea index & $12.56 \pm 5.16 ; 4.10-20.60$ & $10.59 \pm 5.38 ; 3.10-21.30$ & 1.18 & 0.24 \\
\cline { 2 - 6 } & AHI & $39.73 \pm 7.40 ; 28.60-55.80$ & $36.10 \pm 6.35 ; 25.30-48.30$ & 1.65 & 0.11 \\
\cline { 2 - 6 } & ESS & $17.05 \pm 1.70 ; 15-20$ & $16.30 \pm 2.43 ; 13-22$ & 1.13 & 0.27 \\
\hline Postoperative & Minimal SO2 & $95.00 \pm 1.41 ; 92-97$ & $92.65 \pm 2.66 ; 86-96$ & $\mathbf{3 . 4 9}$ & $\mathbf{0 . 0 0 1}^{*}$ \\
\cline { 2 - 7 } & Apnea index & $7.16 \pm 2.22 ; 4-12$ & $13.71 \pm 5.69 ; 5.30-20$ & $\mathbf{4 . 7 9}$ & $<\mathbf{0 . 0 0 1 ^ { * }}$ \\
\cline { 2 - 7 } & Hypopnea index & $9.45 \pm 4.78 ; 1.50-18.10$ & $7.02 \pm 4.52 ; 2.20-21.50$ & 1.65 & 0.11 \\
\cline { 2 - 7 } & AHI & $16.67 \pm 6.06 ; 7.30-28.10$ & $20.72 \pm 4.41 ; 13.30-0.30$ & $\mathbf{2 . 4 2}$ & $\mathbf{0 . 0 2 1 ^ { * }}$ \\
\cline { 2 - 7 } & ESS & $9.10 \pm 2.42 ; 5-17$ & $11.20 \pm 2.33 ; 7-16$ & $\mathbf{2 . 7 9}$ & $\mathbf{0 . 0 0 8 ^ { * }}$ \\
\hline
\end{tabular}

* significant; SO2: oxygen saturation; AHI: apnea hypopnea index; ESS: Epworth Sleepiness Scale.

Table (3): Effect of surgical maneuver on different variables

\begin{tabular}{|l|l|c|c|c|c|}
\hline \multicolumn{2}{|c|}{ Variable } & Group A & Group B & $t$ & P \\
\hline \multirow{3}{*}{$\begin{array}{l}\text { Difference } \\
\text { [Preoperative - postoperative] }\end{array}$} & Minimal SO2 & $9.96 \pm 3.79$ & $6.25 \pm 5.18$ & $\mathbf{2 . 5 8}$ & $\mathbf{0 . 0 1 4 ^ { * }}$ \\
\cline { 2 - 6 } & Apnea index & $20.15 \pm 5.07$ & $11.74 \pm 7.73$ & $\mathbf{4 . 0 6}$ & $<\mathbf{0 . 0 0 1 ^ { * }}$ \\
\cline { 2 - 7 } & Hypopnea index & $3.11 \pm 5.51$ & $3.57 \pm 5.83$ & 0.25 & 0.79 \\
\cline { 2 - 7 } & AHI & $24.78 \pm 4.27$ & $15.38 \pm 4.87$ & $\mathbf{6 . 4 8}$ & $<0.001^{*}$ \\
\cline { 2 - 7 } & ESS & $7.40 \pm 3.21$ & $5.10 \pm 3.04$ & $\mathbf{2 . 3 2}$ & $\mathbf{0 . 0 2 6 ^ { * }}$ \\
\hline
\end{tabular}

* significant; SO2: oxygen saturation; AHI: apnea hypopnea index; ESS: Epworth Sleepiness Scale.

Table (4): Percentage of responders (50\% or more reduction in $\mathrm{AHI}$ or $\mathrm{AHI}<20$ ) among studied groups

\begin{tabular}{|c|c|c|c|c|c|c|c|}
\hline & \multicolumn{2}{|c|}{ Hyoid Suspension } & \multicolumn{2}{|c|}{ Midline Glossectomy } & \multicolumn{2}{|c|}{ Total } \\
\hline & & $\mathrm{n}$ & $\%$ & $\mathrm{n}$ & $\%$ & $\mathrm{n}$ & $\%$ \\
\hline \multirow[t]{2}{*}{ Responders } & Yes & 15 & $75.0 \%$ & 8 & $40.0 \%$ & 23 & $57.5 \%$ \\
\hline & No & 5 & $25.0 \%$ & 12 & $60.0 \%$ & 17 & $42.5 \%$ \\
\hline \multicolumn{2}{|l|}{ Statistics } & \multicolumn{6}{|c|}{$X^{2}=5.01 ; p=0.025^{*}$} \\
\hline
\end{tabular}

${ }^{\text {* }}$ significant

\section{DISUCSSION}

Obstructive sleep apnea (OSA) is defined as a total or partial obstruction of the upper airways during sleep leading to apnea or hypopnea, which affects patient's quality of life and associated with different systemic complications, which put the patient's life at risk[20].

In adults, OSA considered the second most common sleep disorder[21].

Sleep medicine had expanded the management options of OSA. However, the effective interventions based on the identification of the region of the greatest obstruction[22].
The current study introduced the surgical treatment of OSA due to hypopharyngeal obstruction, by modified hyoid bone suspension or midline glossectomy. Results revealed that, both techniques were effective in management of OSA. However, the modified hyoid bone suspension technique is superior than midline glossectomy. The main indicator of superiority of modified hypoid bone suspension maneuver is the percentage of responders $(75.0 \%)$, which was significantly higher than midline glossectomy $(40.0 \%)$.

The principle underlying hyoid bone suspension based on the fact that, hyoid bone is considered as a solid component of the hypopharynx, and the 
anteroinferior movement of the bone with its muscular attachments could lead to widening of the space of the hypopharyngeal airway. In addition, this surgical procedure supports the lateral wall of the hypopharynx by its effect on middle constrictor pharyngeal muscle. Thus, prevents lateral wall collapse, avoid obstruction at the hypopharynx at the level of the tongue base ${ }^{[18,23]}$.

In their work, Askar et al. [24] reported that, hyoid suspension was associated with $10 \%$ of nonresponse, which is lower than the current study. They concluded that hyoid suspension is a safe and effective procedure for treatment of OSA when used alone or as a part of multi-level intervention, and this procedure had no hazards on voice or swallowing.

In a modified hyoid suspension technique, ElAnwar and Askar[25] included 19 patients, and reported that, AHI significantly decreased from $51.5 \pm 11.9$ preoperative level to $10.1 \pm 4.9$ postoperatively. The mean lowest $\mathrm{SO} 2$ increased significantly from $79.2 \pm 10.2$ to $89.5 \pm 8.1$. Furthermore, ESS showed significant reduction from $13.8 \pm 2.9$ preoperatively, to $5.3 \pm 2.9$ at 6 months postoperatively. These results confirmed by the current study.

Piccin et al.[18] in a case control study of 27 patients to examine effectiveness of hyoid suspension as a sole technique, reported a significant reduction of $\mathrm{AHI}$ from 36 to 11, with surgical success rate of $76.0 \%$ (comparable to the current work).

Verse et al.[26] recommended that, isolated hyoid suspension can be used as a surgical treatment of OSA in patients with suspected hypoglossal obstruction.

Results of the current study go in agreement with Elbanhawy et al.[27] who reported that, in hyoid suspension group, the $\mathrm{AHI}$ decreased from preoperative $38.40 \pm 10.54$ to postoperative $15.47 \pm$ 12.61 with a statistical significance. In addition, mean oxygen saturation increased from preoperative $73.07 \pm 4.99$ to postoperative $83.73 \pm 7.19$ with a statistical significance.

Stuck et al. [28] reported results of 15 patients received isolated hyoid suspension; the $\mathrm{AHI}$ was significantly reduced from preoperative $35.2 \pm 19.1$ to postoperative $27.4 \pm 26.2$, and $40 \%$ of the patients were responders. Daytime sleepiness had been also improved significantly.

On the other side, Bowden et al. [29] did not find such good results of hyoid suspension for 29 patients; only five of 29 patients $(17.2 \%)$ had a successful outcome. The AHI did not significantly change at preoperative when compared to preoperative values, although the minimum oxygen saturation did show some improvement (from 72.7\% to $77.0 \%$ ).

Fujita et al. [12] reported on an initial experience for midline glossectomy on 12 patients, and reported a response rate of $42.0 \%$ (comparable to the current work) with significant reduction of AHI from 37.6 to 6.2. Another two studies; reported a response rate of $60.0 \%$ when midline glossectomy combined with UPPP [30,31].

In the current study, there was pain and dysphagia in all patients in the first postoperative week. Analgesics had been used and were effective in treatment. In addition, no infection had been observed. Richard et al. [32], reported a deviated tongue in one patient for a short period, which resolved within a few postoperative weeks, a wound abscess reported in another case and fistula in two patients, who needed more surgical interventions. Hou et al.,[33], two patients had perioperative tongue swelling. These patients need ICU admission and they had been extubated in the day after surgery.

The variability in reported results among the different studies could be attributed to different inclusion and exclusion criteria; small number of patients included in the majority of studies and different definition of responders.

The main strengths of the current work included the prospective nature and sufficient number of patients included in each group. In addition, a follow up of 6 months could be considered a relatively sufficient period. However, the current study had a limitation, such as the absent assessment of voice postoperatively.

In short, results of the current study support the superiority of modified hyoid suspension over the midline glossectomy, as a safer and more effective procedure for treatment of OSA.

\section{Financial and Non-Financial Relationships and Activities of Interest}

None 


\section{REFERENCES}

1. Garvey JF, Pengo MF, Drakatos P, Kent BD. Epidemiological aspects of obstructive sleep apnea. $J$ Thorac Dis. 2015;7(5):920-9. [DOI: 10.3978/j.issn. 2072-1439.2015.04.52].

2. Patel SR. Obstructive Sleep Apnea. Ann Intern Med. 2019 3; 171 (11): ITC81-ITC96. [DOI: 10.7326/AITC 201912030].

3. Arnaud C, Bochaton T, Pépin JL, Belaidi E. Obstructive sleep apnoea and cardiovascular consequences: Pathophysiological mechanisms. Arch Cardiovasc Dis. 2020 May;113(5):350-358. [DOI: 10.1016/j.acvd. 2020.01.003].

4. Ralls F, Cutchen $L$. A contemporary review of obstructive sleep apnea. Curr Opin Pulm Med. 2019 Nov; 25(6): 578-593. [DOI: 10.1097/ MCP. 0000000000000623].

5. Genta PR, Schorr F, Eckert DJ, Gebrim E, Kayamori F, Moriya HT, Malhotra A, Lorenzi-Filho G. Upper airway collapsibility is associated with obesity and hyoid position. Sleep. 2014 Oct 1;37(10):1673-8. [DOI: 10.5665/sleep.4078].

6. Kuna ST, Reboussin DM, Borradaile KE, Sanders MH, Millman RP, Zammit G, et al. Long-term effect of weight loss on obstructive sleep apnea severity in obese patients with type 2 diabetes. Sleep. 2013 May 1; 36(5):641-649A. [DOI: 10.5665/sleep.2618].

7. Garbarino S, Guglielmi O, Campus C, Mascialino B, Pizzorni D, Nobili L, Mancardi GL, Ferini-Strambi L. Screening, diagnosis, and management of obstructive sleep apnea in dangerous-goods truck drivers: to be aware or not? Sleep Med. 2016 Sep; 25:98-104. [DOI: 10.1016/j.sleep.2016.05.015].

8. Johnson DM, Soose RJ. Updated Nasal Surgery for Obstructive Sleep Apnea. Adv Otorhinolaryngol. 2017; 80:66-73. [DOI: 10.1159/000470868].

9. Fujita S. Pharyngeal surgery for obstructive sleep apnea and snoring. In: Fairbanks DNF, Fujita S. Ikematsu T, Simmons FB, editors. Snoring and obstructive sleep apnea. New York: Raven Press; 1987. p.101-28.

10. Simmons FB, Guilleminault C, Miles LE. A surgical treatment for snoring and obstructive sleep apnea. West J Med. 1984 Jan;140(1):43-6. [PMID: 6702191].

11. Phua CQ, Yeo WX, Su C, Mok PKH. Multi-level obstruction in obstructive sleep apnoea: prevalence, severity and predictive factors. J Laryngol Otol. $2017 \mathrm{Nov;131} \mathrm{(11):}$ 982-986. [DOI: 10.1017/S0022215117001906].

12. Fujita S, Conway W, Zorick F, Roth T. Surgical correction of anatomic azbnormalities in obstructive sleep apnea syndrome: uvulopalato-pharyngoplasty. Otolaryngol Head Neck Surg. 1981 Nov-Dec;89(6):923-34. [DOI: 10.1177/019459988108900609].

13. Sher AE. Update on upper airway surgery for obstructive sleep apnea. Curr Opin Pulm Med. 1995 Nov; 1(6): 504-11. [DOI: 10.1097/00063198-199511000-00013].
14. Kezirian EJ, Hussey HM, Brietzke SE, Cohen SM, Davis GE, Shin JJ, Weinberger DG, Cabana MD. Hypopharyngeal surgery in obstructive sleep apnea: practice patterns, perceptions, and attitudes. Otolaryngol Head Neck Surg. 2012 Nov;147(5):96471. [DOI: $10.1177 / 0194599812453000]$.

15. Riley RW, Powell NB, Guilleminault C. Maxillofacial surgery and nasal CPAP. A comparison of treatment for obstructive sleep apnea syndrome. Chest. 1990 Dec;98(6):1421-5. [DOI: 10.1378/chest.98.6.1421].

16. Riley RW, Powell NB, Guilleminault C. Obstructive sleep apnea syndrome: a surgical protocol for dynamic upper airway reconstruction. J Oral Maxillofac Surg. 1993 Jul;51(7):742-7. [DOI: 10.1016/s0278-2391(10) 80412-4].

17. Hurlston A, Foster SN, Creamer J, Brock MS, Matsangas P, Moore BA, Mysliwiec V. The Epworth Sleepiness Scale in Service Members with Sleep Disorders. Mil Med. 2019 Dec 1;184(11-12):e701e707. [DOI: 10.1093/milmed/usz066].

18. Piccin O, Scaramuzzino G, Martone C, Marra F, Gobbi R, Sorrenti G. Modified hyoid suspension technique in the treatment of multilevel related obstructive sleep apnea. Otolaryngol Head Neck Surg. 2014 Feb;150 (2): 321-4. [DOI: 10.1177/0194599813514532].

19. Suh GD. Evaluation of open midline glossectomy in the multilevel surgical management of obstructive sleep apnea syndrome. Otolaryngol Head Neck Surg. 2013; 148 (1): 166-71. [DOI: 10.1177/0194599812464331].

20. Hadad H, Mendes BC, Lima VN, Ferraz FWDS, Souza FÁ, Magro Filho 0. Strategy for Optimizing Airway Volume with Genioglossal Advancement Using Cutting Guide in the Treatment of Obstructive Sleep Apnea. J Craniofac Surg. 2020 Mar/Apr;31(2):558561. DOI: $10.1097 /$ SCS.0000000000006083.

21. Senaratna CV, Perret JL, Lodge CJ, Lowe AJ, Campbell BE, Matheson MC, Hamilton GS, Dharmage SC. Prevalence of obstructive sleep apnea in the general population: A systematic review. Sleep Med Rev. 2017;34:70-81. [DOI: 10.1016/j.smrv.2016.07.002].

22. Barrera JE. Skeletal Surgery for Obstructive Sleep Apnea. Otolaryngol Clin North Am. 2016 Dec;49(6):14331447. [DOI: 10.1016/j.otc.2016.07.006].

23. Canzi P, Berardi A, Tinelli C, Montevecchi F, Pagella F, Vicini C, Benazzo M. Thirteen Years of Hyoid Suspension Experience in Multilevel OSAHS Surgery: The Short-Term Results of a Bicentric Study. Int J Otolaryngol. 2013; 2013:263043. [DOI: 10.1155/ 2013/263043].

24. Askar SM, Quriba AS, Hassan EM, Awad AM, Bessar AA. Voice and Swallowing Outcomes after Hyoid Suspension Surgery in Patients with Obstructive Sleep Apnea. Folia Phoniatr Logop. 2017;69(5-6): 271-277. [DOI: 10.1159/000488239]. 
25. El-Anwar MW, Askar SM. Hyoid Periosteum Sutures: A Modified Tissue-Preserving Hyoid Suspension Technique for Obstructive Sleep Apnea. J Craniofac Surg. 2019 May/Jun;30(3):e231-e233. [DOI: 10.1097/SCS.0000000000005187]

26. Verse T, Dreher A, Heiser C, Herzog M, Maurer JT, Pirsig $\mathbf{W}$, et al. ENT-specific therapy of obstructive sleep apnoea in adults : A revised version of the previously published German S2e guideline. Sleep Breath. 2016 Dec;20(4):1301-1311. [DOI: 10.1007/s11325-0161353-9].

27. Elbanhawy OA, Abd Elshafy IA, Khaleel YA, Elhelbawy RH, Abd Elhameed AF. Hyoid suspension versus laser midline glossectomy in the management of obstructive sleep apnea. Menoufia Med J 2018; 31:244-9. [DOI: 10.4103/1110-2098.234213]

28. Stuck BA, Neff W, Hörmann K, Verse T, Bran G, Baisch A, Düber C, Maurer JT. Anatomic changes after hyoid suspension for obstructive sleep apnea: an MRI study. Otolaryngol Head Neck Surg. 2005 Sep;133(3):397-402. [DOI: 10.1016/j.otohns. 2005. 06.002]

29. Bowden MT, Kezirian EJ, Utley D, Goode RL. Outcomes of hyoid suspension for the treatment of obstructive sleep apnea. Arch Otolaryngol Head Neck Surg. 2005; 131 (5): 440-5. [DOI: 10.1001/archotol. 131. 5.440].
30. Elasfour A, Miyazaki S, Itasaka Y, Yamakawa K, Ishikawa K, Togawa K. Evaluation of uvulopalatopharyngoplasty in treatment of obstructive sleep apnea syndrome. Acta Otolaryngol Suppl. 1998; 537: 52-6. [DOI: 10.1080/ 00016489850182369].

31. Andsberg $U$, Jessen M. Eight years of follow-up-uvulopalatopharyngoplasty combined with midline glossectomy as a treatment for obstructive sleep apnoea syndrome. Acta Otolaryngol Suppl. 2000; 543: 175-8. [DOI: 10.1080/000164800454323].

32. Richard W, Timmer F, van Tinteren $\mathbf{H}$, de Vries $\mathbf{N}$. Complications of hyoid suspension in the treatment of obstructive sleep apnea syndrome. Eur Arch Otorhinolaryngol. 2011 Apr;268(4):631-5. [DOl: $10.1007 /$ s00405-010-1419-4].

33. Hou J, Yan J, Wang B, Zhu K, Sheng Y, Zheng G, Kang Q. Treatment of obstructive sleep apnea-hypopnea syndrome with combined uvulopalatopharyngoplasty and midline glossectomy: outcomes from a 5-year study. Respir Care. 2012 Dec;57(12):2104-10. [DOI: 10.4187/respcare.01695]. 